\title{
Top Energy Saver of the Year: Results of an Energy Saving Competition in Public Buildings
}

\author{
Jan KASELOFSKY ${ }^{1 *}$, Ralf SCHÜLE ${ }^{2}$, Marika ROŠ $\bar{A}^{3}$, Toms PRODAN̦UKS ${ }^{4}$, \\ Anda JEKABSONE ${ }^{5}$, Edina VADOVICS ${ }^{6}$, Kristóf VADOVICS ${ }^{7}$, Thekla HEINEL ${ }^{8}$ \\ ${ }^{1}$ Wuppertal Institut, Doeppersberg 19, 42103 Wuppertal, Germany \\ ${ }^{2}$ Federal Institute for Research on Building, Urban Affairs and Spatial Development, \\ Deichmanns Aue 31-37, 53179 Bonn, Germany \\ ${ }^{3-5}$ Riga Technical University, 1 Kalku Street, Riga LV-1658, Latvia \\ ${ }^{6,7}$ GreenDependent Institute, 2100 Gödöllö, Éva u. 4., Hungary \\ ${ }^{8} B \& S U$, Alexanderstraße 7, 10178 Berlin, Germany
}

\begin{abstract}
Non-residential buildings in the European Union consume more than one third of the building sector's total. Many non-residential buildings are owned by municipalities. This paper reports about an energy saving competition that was carried out in 91 municipal buildings in eight $\mathrm{EU}$ member states in 2019. For each public building an energy team was formed. The energy teams' activities encompassed motivating changes in the energy use behaviour of employees and small investments. Two challenges added an element of gamification to the energy saving competition. To assess the success of the energy saving competition, an energy performance baseline was calculated using energy consumption data of each public building from previous years. Energy consumption in the competition year was monitored on a monthly base. After the competition the top energy savers from each country were determined by the percentage-based reduction of energy consumption compared to the baseline. On average, the buildings had an electricity and heat consumption in 2019 that was about $8 \%$ and $7 \%$, respectively, lower than the baseline. As an additional data source for the evaluation, a survey among energy team members was conducted at the beginning and after the energy competition. Support from superiors, employee interest and motivation and behaviour change as assessed by energy team members show a positive, if weak or moderate, correlation with changes in electricity consumption, but not with changes in heat consumption.
\end{abstract}

Keywords - Energy use behaviour; non-residential buildings; workplace

\section{INTRODUCTION}

Non-residential buildings are an under-researched area. The fact that the latest year for which data on the energy consumption of non-residential buildings can be found in the EU buildings database is 2014 emphasizes this point. In 2014 non-residential buildings in the European Union consumed more than $1640 \mathrm{TWh}$ of energy [1]. This was more than one third of building sector's total energy consumption. When it comes to non-residential buildings, one important stakeholder are local authorities. They own and operate a considerable number of non-residential buildings. Among these are administrative buildings like the city hall and

* Corresponding author.

E-mail address: jan.kaselofsky@wupperinst.org

C2020 Jan Kaselofsky, Ralf Schüle, Marika Rošā, Toms Prodaņuks, Anda Jekabsone, Edina Vadovics, Kristóf Vadovics,

Thekla Heinel. This is an open access article licensed under the Creative Commons Attribution License

(http://creativecommons.org/ licenses/by/4.0), in the manner agreed with Sciendo. 
buildings for municipal departments, kindergartens and schools to educate younger citizens, cultural buildings like museums and assembly halls as well as health buildings like hospitals and health centres. An obvious approach to lower the energy consumption of these buildings is to renovate them by increasing the energy efficiency of the heating system, the building envelope and windows. While this will be necessary to attain long-term energy demand and greenhouse gas emission goals, an intermediate approach can be to influence the energy use behaviour of persons using these buildings, i.e. the people working and studying in them.

One of the objectives of the Horizon 2020 project Compete4SECAP, funded by the European Commission, was to conduct an energy saving competition in public buildings to see to what extent strategies of this kind can help to lower energy demand of municipalities. Local authorities from eight member states of the European Union participated in the project Compete4SECAP, namely Croatia, Cyprus, France, Germany, Hungary, Italy, Latvia and Spain.

This paper reports on the energy saving competition implemented in 2019 and its results. It is structured as follows: first, literature about interventions to change energy use behaviour in non-residential buildings is reviewed. Afterwards, we present the activities that have taken place during the energy saving competition and give background information on the buildings the energy saving competition took place in. The next section describes how we evaluated the energy saving competition - both with regard to energy savings attained as well as the survey conducted among the members of the energy teams that were tasked with promoting the energy saving competition in their buildings. Results for energy savings attained during the energy saving competition and from the survey are elaborated in the subsequent section. The paper concludes with lessons learnt, a discussion of the study's limitations and further research needs.

\subsection{Literature Review}

User behaviour has a non-negligible importance for energy consumption. Today, even building simulations aim to take user behaviour into account [2]. Interventions to change energy use behaviour have the potential to help reduce energy demand, avoid greenhouse gas emissions and reduce energy costs. Various interventions that intent to change user behaviour in residential buildings have been studied. Reviews find that non-price interventions can reduce energy consumption [3] and that energy savings between $2 \%$ and $20 \%$ are possible [4]. Yet, many studies try to change energy use behaviour in residential buildings, and similar interventions in non-residential buildings are studied less often. Staddon et al. review 22 studies of interventions to change energy use behaviour in the workplace [5]. As the Compete4SECAP energy saving competition took place in buildings, to which people come either to work or to study (for more details see the subsequent section), studies dealing with interventions to change energy use behaviour at the workplace are of high relevance. The fact that the intervention to change energy use behaviour happens at the workplace has several consequences. In most cases, energy cost savings will not work as monetary incentive. Furthermore, employees trying to change their energy use behaviour could experience what Bull and Janda [6] name competing priorities. Considering the various duties and tasks employees must perform, the repercussions of their actions on energy consumption are given low priority. Based on focus groups and interviews in one public authority in the United Kingdom, Bull and Janda [6] note that this is an existing concern. On the other hand, there are factors associated with workplaces and schools that can help to make interventions more successful. One of these factors is their communal nature. 
Staddon et al. [5] point out that workplace behaviour is driven by social and group norms. Thus, a lasting change of these norms can induce abiding reductions in energy consumption. Staddon et al. also refer to a sense of community within organisations that interventions can leverage to achieve larger impacts [5]. Awards and incentives given publicly constitute a further element that can be used for interventions in a workplace-setting and may make them more effective.

Staddon et al. [5] developed a classification of interventions, which will be used subsequently to classify the interventions during the Compete4SECAP energy saving competition. For this reason, the most important types of interventions will be defined in detail below [5]:

- Education: "Increasing knowledge or understanding";

- Persuasion: "Using communication to induce positive or negative feelings or stimulate action";

- Incentivisation: "Creating expectation of reward";

- Environmental restructuring: "Changing the physical or social context";

- Modelling: "Providing an example for people to aspire or imitate";

- Enablement: "Increasing means/reducing barriers to increase ability or opportunity".

Of the 22 studies Staddon et al. [5] review, just one makes use of only one type of intervention, while the others use three or more interventions. It is also important to note that the borders between interventions are not delineated distinctly. One and the same instrument may at times constitute two different interventions or even more.

Looking at the energy savings achieved during these studies, one can find wildly differing success of the interventions [5]. Seven studies report energy savings of 20 percent or more. Though, it has to be noted that five of these studies achieved the energy savings by introducing an element of automation.

Many of the studies reviewed by Staddon et al. [5] utilised internal challenges, competitions and comparisons of the saving success between colleagues as interventions. Gustafson and Longland [7] describe a behavioural program using many of the instruments that have been also used during the Compete4SECAP energy saving competition. Individual colleagues have been appointed conservation floor captains (comparable to the building energy teams in Compete4SECAP), floor challenges have been conducted, stickers and posters provided information and persuasion and energy saving tips were emailed on a regular base. Energy consumption reduced by $5 \%$ after the first year of the intervention and an additional $4 \%$ after the second year [7]. Metzger et al. [8] found that an energy saving competition in an administrative building in the United States lowered electricity consumption by $6 \%$. The competition took place over a period of four months. Many studies reporting about interventions to change energy use behaviour were conducted within universities. Murtagh et al. [9] describe a trial that targeted office workers in a university building. The intervention was to install energy use monitors, give feedback on individual energy use and tips how to save energy. Over the four-week study period, Murtagh et al. measured a significant reduction of electricity consumption by up to approximately $16 \%$ [9]. Looking to explain reduction success by surveying participants and conducting focus groups, Murtagh et al. [9] only found a significant relationship between attitudes to energy conservation and energy use. It is important for the interpretation of survey results to be discussed subsequently that Murtagh et al. [9] note that self-reported energy use behaviour had no relationship with actual energy use behaviour in their sample. The study by Dixon et al. [10] is notable to the extent that they conduct a controlled trial of a comparative feedback campaign in a university setting. Dixon et al. [10] identify significant reductions in energy consumption in five of the six 
buildings that were treated with the intervention, amounting to $6.5 \%$ in total. They also observe that the perception of descriptive norms, i.e. the extent to which respondents believe that others are undertaking energy conservation behaviour, significantly increased during the intervention [10]. This is a good sign that group norms can be changed during interventions and lead to improved energy use behaviour. Petersen et al. [11] describe an energy saving competition in university dorms that had more than 300000 participants during the two-year study. A survey was conducted to identify factors that help to explain success in the competition. Awareness of the competition and motivation to participate in the competition had a significant positive correlation with the reduction in electricity use. Petersen et al. [11] also find a positive correlation between the perception of the degree to which other students are motivated to participate in the competition. Overall reductions of electricity consumption attained in the study by Petersen et al. were $4 \%$ [11]. Further information on studies utilising energy saving competition can be found in Vine and Jones [12], who review energy saving competitions in residential and non-residential settings.

The Compete4SECAP energy saving competition built on experiences made during an earlier Horizon2020 project named save@work. The energy saving competition during save@work took place in 176 public buildings in nine European countries. The instruments employed during this energy saving competition are similar to those described in the subsequent section. Reductions in energy consumption were observed in $73 \%$ of the buildings and energy consumption decreased by $8 \%$ on average and by $20-25 \%$ in the best performing buildings [13]. While the save@work project strictly focused on energy competitions and most of the activities were implemented by experts in collaboration with local authorities, the scope of the COMPETE4SECAP energy saving competition was different. Here the energy saving competition was implemented as part of efforts to introduce an energy management system for the local authorities. The responsibility for running the energy saving competition was assigned to energy managers of these local authorities. Therefore, researcher effort and time devoted to the energy saving competition was considerably lower than during the earlier project.

\section{MethodS}

The subsequent subsections describe the methods that have been employed in implementing the energy saving competition and in evaluating its results. Data to evaluate the energy saving competition's success mainly comes from two sources. Data on energy consumption for all non-residential buildings taking part in the competition has been collected continuously during the competition. Additionally, two surveys among energy team members have been conducted in the first months of the energy saving competition and after the energy saving competition has ended.

\subsection{The Energy Saving Competition}

The activities of the energy saving competition can be clustered into three groups:

1. Preparations: Selection of the participating buildings, collection of reference data, appointment of the building level energy team members, development of support materials, and training of the energy team members;

2. Implementation phase: Monthly reading of the energy meters and the local activities the energy teams performed to actively involve their colleagues working in the same building with the continuous professional support from the project partners in the form of facilitating 
internal challenges and organizing motivational workshops;

3. Evaluation and award ceremony for the winners.

\subsection{Preparations}

Prior to the announcement of the energy saving competition the project partners had developed generic rules for the competition (number of participating buildings per local authority, types of buildings allowed to enter the competition, evaluation system, awards, etc.). In the next step three 'office style' public buildings were chosen in every participating local authority. In few of the Compete4SECAP countries buildings other than typical office buildings were chosen for the competition. Examples for this are schools and kindergartens (classified as education buildings), assembly halls and libraries (classified as cultural buildings), health centres (classified as health buildings) and even one research institution (classified as research building). We also had to observe drop-out during the competition: One municipality dropped out of the energy saving competition due to staff shortages. Another municipality eliminated one building from the competition due to imminent renovation measures. Table 1 gives an overview of the number of local authorities and buildings taking part in the energy saving competition until its end.

TABle 1. BAsic DAta on Buildings in the EnERGy SAVING COMPETITION

\begin{tabular}{|c|c|c|c|c|c|c|}
\hline Country & $\begin{array}{l}\text { No. of local } \\
\text { authorities in } \\
\text { competition }\end{array}$ & $\begin{array}{l}\text { No. of } \\
\text { buildings in } \\
\text { competition }\end{array}$ & $\begin{array}{l}\text { Classification } \\
\text { of buildings }\end{array}$ & $\begin{array}{l}\text { Total floor area } \\
\text { of buildings in } \\
\text { competition }\end{array}$ & $\begin{array}{l}\text { Baseline electricity } \\
\text { consumption }\end{array}$ & $\begin{array}{l}\text { Baseline heat } \\
\text { consumption }\end{array}$ \\
\hline Croatia & 4 & 12 & $\begin{array}{l}\text { Administration, } \\
\text { education }\end{array}$ & $17701 \mathrm{~m}^{2}$ & 1139.1 MWh & $1678.2 \mathrm{MWh}$ \\
\hline Cyprus & 4 & 12 & $\begin{array}{l}\text { Administration, } \\
\text { culture, } \\
\text { education, } \\
\text { health, research }\end{array}$ & $24527 \mathrm{~m}^{2}$ & 1015.8 MWh & Not applicable* \\
\hline France & 4 & 12 & $\begin{array}{l}\text { Administration, } \\
\text { culture, } \\
\text { education }\end{array}$ & $42440 \mathrm{~m}^{2}$ & $1767.9 \mathrm{MWh}$ & $2885.6 \mathrm{MWh}$ \\
\hline Germany & 3 & 9 & Administration & $16513 \mathrm{~m}^{2}$ & $568.0 \mathrm{MWh}$ & 1049.0 MWh \\
\hline Hungary & 4 & 10 & Administration & $25094 \mathrm{~m}^{2}$ & $1248.6 \mathrm{MWh}$ & $2725.2 \mathrm{MWh}$ \\
\hline Italy & 3 & 9 & $\begin{array}{l}\text { Administration, } \\
\text { culture, } \\
\text { education }\end{array}$ & $21126 \mathrm{~m}^{2}$ & $338.3 \mathrm{MWh}$ & $2220.4 \mathrm{MWh}$ \\
\hline Latvia & 4 & 15 & $\begin{array}{l}\text { Administration, } \\
\text { culture, } \\
\text { education }\end{array}$ & $18180 \mathrm{~m}^{2}$ & 462.2 MWh & $2223.4 \mathrm{MWh}$ \\
\hline Spain & 4 & 12 & $\begin{array}{l}\text { Administration, } \\
\text { culture, } \\
\text { education, } \\
\text { health }\end{array}$ & $38416 \mathrm{~m}^{2}$ & $2838.7 \mathrm{MWh}$ & Not applicable* \\
\hline Total & 30 & 91 & & $203997 \mathrm{~m}^{2}$ & 9378.6 MWh & $12781.8 \mathrm{MWh}$ \\
\hline
\end{tabular}


An energy team was formed in each building, including at least two employees, in order to implement the energy saving competition locally. The team members collected the historical reference energy consumption data for the respective buildings compared to which the energy saving had to be realised by the end of the competition year.

Meanwhile the project partners developed a great variety of supporting materials the local energy teams could utilise and choose from, including several templates as reminders (stickers and door/window hangers, posters). In addition, each public authority was given a set of tools (energy and/or indoor climate meters and recorders) to help identify the energy saving opportunities and to monitor the results of the buildings. The templates for visual materials were translated to the national languages by the project partners.

Finally, a one-day-long training was provided by the project partners to the members of the energy teams at the beginning of the competition, during which special attention was paid to motivational activities that could be used during the competition to involve employees in energy saving activities. Another objective of the training was to give energy teams' knowledge and skills on how to make a simple energy audit or inspection of a building. A 40-pages-long Strategic Handbook was developed to provide specific methodological and conceptual input to the local public volunteers.

\subsection{Implementation}

Each energy team prepared an annual action plan detailing what type of actions and methods they intended to use for involving their fellow workers in their own buildings. These activities included the utilization of the support materials the project partners had provided, the monthly collection and reporting of the energy use data, communication of the competition results, etc.

Supplementing these local efforts, the project partners organized at least two internal challenges (topic related quizzes, photo contest, best energy saving practices as posts on social networks etc.) for the public employees during the energy saving competition period. The winners of the internal challenges were awarded by small, symbolic prizes. Furthermore, local or national motivational workshops were also organized for all energy team members in the second half of the competition year in order to exchange experiences, discuss problematic issues and so far, achieved energy saving results as well as to give motivation to continue the energy saving competition.

The instruments utilised during the Compete4SECAP energy saving competition are classified according to the types of interventions developed by Staddon et al. [5]. It must be noted that instruments could be either targeted at the members of building energy teams or both target groups of the energy saving competition (i.e. employees and building energy team members). Table 2 shows the results of this classification.

\section{TABLE 2. INSTRUMENTS UTILISED DURING THE COMPETE4SECAP ENERGY SAVING} COMPETITION

\begin{tabular}{lll}
\hline Instrument & Intervention & Target group \\
\hline Energy savings tips & Education, Persuasion & Both \\
Motivational workshops & Education, Persuasion & Energy team members \\
Internal challenges & Incentivisation, Modelling & Both \\
\hline
\end{tabular}




\begin{tabular}{|c|c|c|}
\hline $\begin{array}{l}\text { Monthly newsletter (incl. data } \\
\text { on energy savings achieved to } \\
\text { date) }\end{array}$ & Education, Persuasion, Modelling & Both \\
\hline $\begin{array}{l}\text { Checklist to identify energy } \\
\text { saving potentials }\end{array}$ & Education & Energy team members \\
\hline $\begin{array}{l}\text { Information materials (door } \\
\text { hangers, posters, stickers, } \\
\text { etc.) }\end{array}$ & Persuasion, Environmental restructuring & Both \\
\hline $\begin{array}{l}\text { Technical materials } \\
\text { (thermometers, air quality } \\
\text { monitors, power strips, etc.) }\end{array}$ & Environmental restructuring, Enablement & Both \\
\hline
\end{tabular}

\subsection{Evaluation and Award Ceremony}

After the one-year-long energy saving competition the final energy use data was collected and the best performing buildings were awarded on a national level in the framework of an awarding ceremony combined with a national conference, where the winners shared their experience, tricks and success methods with not only the employees of the participating local authorities but also other interested parties (other municipalities, representatives of the press, NGOs, expert bodies, etc.). A very important element of the competition subsequent to evaluation is celebration which ought also to receive attention so participants are motivated to continue the acquired energy saving behaviour.

\subsection{Collection of Energy Consumption Data and Calculation of Energy Savings}

A general methodology was developed to determine monthly and annual energy savings during the energy saving competition in public buildings in eight countries. First, historical energy consumption data for each public building were gathered. For this purpose, each of the local authority (LA) compiled specific data collection templates with monthly data on heat and electricity consumption and average outdoor temperature for the last three years. In order to ensure reliable and credible data analysis and results, monthly data were collected.

If data were missing or not available for three years, historical data for the previous year or two-year period, before major changes (e.g. renovation of the building envelope) was used. Buildings with data for less than one year or 12 months were excluded. It was also defined that a building could still participate if only data for either electricity or heat consumption was available. However, savings during the competition were calculated only for the type of energy for which historical data was available.

After the collection of the historical (reference) energy consumption and outdoor air temperature, baseline energy consumption was derived for each building. Two separate baselines were created, one for electricity and one for heating in relation to outdoor air temperature. Outdoor air temperature was used as it is one of the main factors influencing energy consumption of buildings. Total energy consumption is the sum of electricity and heat baselines.

During the competition period (January - December 2019) LA representatives recorded heat and electricity consumption $\left(Q_{\text {competition }}\right)$ and outdoor air temperature data separately for each month and entered them into an energy monitoring system. Once monthly data was inserted, baseline consumption ( $\left.Q_{\text {baseline}}\right)$ is calculated by using the formulas created during historical (reference) data analysis. 


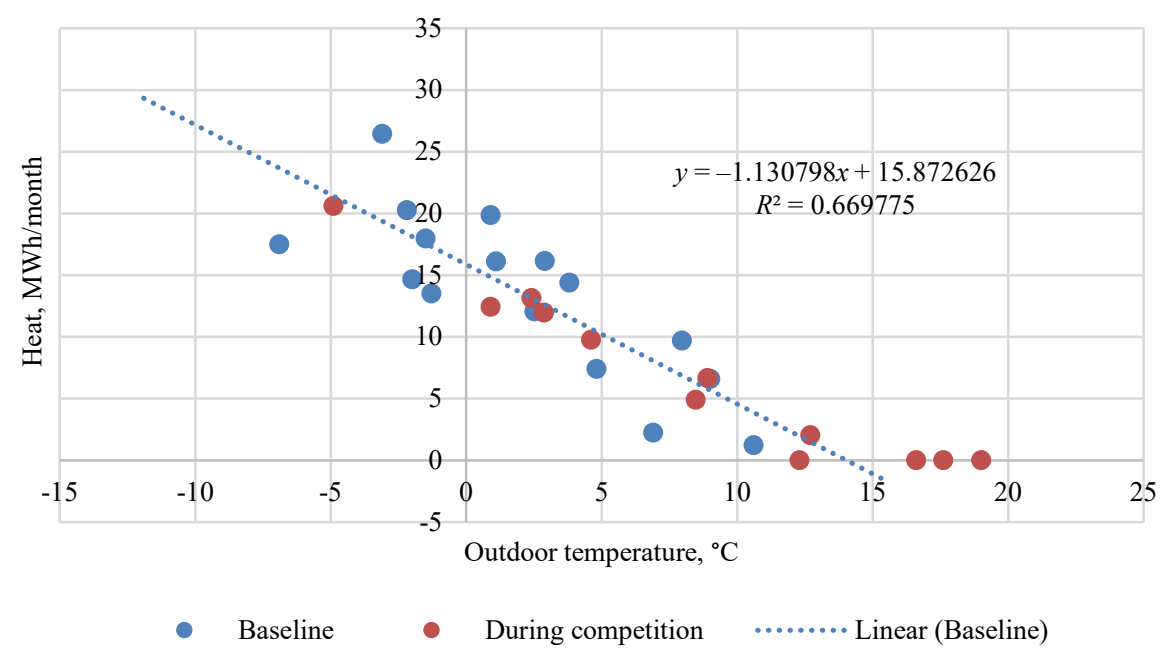

Fig. 1. An example of heat energy baseline determination.

$Q_{\text {baseline }}$ is calculated as $y$ in the equation seen in Fig. 1, where $x$ is the outdoor temperature. When $Q_{\text {competition }}$ is determined during the competition, absolute monthly and yearly energy savings ( $\left.Q_{\text {savings }}\right)$ are calculated by using Eq. (1).

$$
Q_{\text {savings }}=Q_{\text {baseline }}-Q_{\text {competition }}, \mathrm{MWh} / \text { month }
$$

Accumulated energy savings are calculated in order to estimate the total energy savings during the respective period of the energy competition. It allows also participants of the competition to follow energy saving results and take further actions. The calculation of $Q_{\text {savings }}$ is repeated each month. To calculate the cumulative or total savings ( $\left.Q_{\text {total_savings }}\right)$ during the competition period all individual monthly energy saving results are summarized.

To determine the winner of energy saving competition, $Q_{\text {savings }}$ are expressed in percentage ( $\left.q_{\text {savings }}\right)$ by using Eq. (2).

$$
q_{\text {savings }}=\frac{Q_{\text {savings }}}{Q_{\text {baseline }}} \cdot 100, \%
$$

Energy savings, expressed in percentage, were used to compare buildings irrespective of their size and type. This allows to accurately determine the winner of the energy saving competition.

\subsection{Surveys among Energy Team Members}

Members of the energy team were asked to participate in two surveys. The first wave of the survey among energy team members was conducted in February and March 2019. The second wave of the survey was conducted after the energy saving competition had ended in January and February 2020. The questionnaires were drafted in English and have been translated by members of the project consortium to their respective national language. One of the goals of the survey was to assess the extent to which differences in certain qualitative variables can 
help to explain differences in the success during the energy saving competition. To do this, we use the following items from the second wave of the survey:

- The energy team members' rating of their superiors' interest in the energy saving competition, their motivation to support it and its success as well as the extent to which they supplied necessary resources on a five-point agreement scale (strongly disagree to strongly agree);

- Energy team members were asked to estimate how interested their colleagues have been in the energy saving competition, how motivated they have been to contribute to the energy saving competition and to which extent they have changed their energy use behaviour. To do this, respondents entered percentage shares on a five-point scale ranging from e.g. very motivated to not motivated. This type of questions is similar to those used by Petersen et al. [11];

- Energy team members were asked to assess how helpful the materials distributed by the project teams have been on a five-point scale from not helpful to very helpful and rate the materials on a scale from very dissatisfied to very satisfied.

Based on survey results we construct five scores. To do this, we assume that the level of measurement of the scales we use in the survey is interval. These are the five scores we will consider in the analysis:

- Support from superiors: The calculation of this score is based on three items: "My superiors were interested in the energy saving competition and its success", "My superiors were motivated to support the energy saving competition and its success" and "My superiors did supply resources (money and time) we asked for". Answers are transformed into numbers using the values in Table 3. The score for an individual energy member is calculated by averaging. The maximum score is 5 (strongly agree with all three items), the minimum score is 1 (strongly disagree with all three items). If more than one energy team member from a building answers this question, we derive the score for a building by calculating the average of all scores from energy team members from this building;

- Interest: This score is calculated using the estimate share of colleagues that have been very interested, interested, and so on (see Table 3). The score for interest is the weighted mean of the values in Table 3 , where the shares given by respondents are the weights. The maximum score possible is 5 (100\% of colleagues are very interested), the minimum score is 1 (100\% are not interested). If more than one energy team member from a building answers this question, we derive the score for a building by calculating the average of all scores from energy team members from this building;

- Motivation: This score is calculated in the same way as "Interest";

- Behaviour change: This score is calculated in the same way as "Motivation";

- Helpful material: This score is calculated using the assessment of the helpfulness of the materials distributed by the Compete4SECAP team. Respondents were asked to assess eight materials. A score was calculated for every energy team member who assessed at least five. The maximum score possible is $5(100 \%$ of the materials evaluated are rated "very helpful"), the minimum score is 1 (100\% of the materials evaluated are rated "not helpful at all"). If more than one energy team member from a building answers this question, we derive the score for a building by calculating the average of all scores from energy team members from this building. 
TABLE 3. CALCULATION OF SCORES

\begin{tabular}{lllll}
\hline \multicolumn{1}{c}{ Support } & Interest & Motivation & Behaviour change Helpful material \\
\hline 5 Strongly agree & Very interested & Very motivated & To a great extent & Very helpful \\
4 Agree & Interested & Motivated & Somewhat & Helpful \\
3 Undecided & Fairly interested & Fairly motivated & Little & Moderately helpful \\
2 Disagree & Slightly interested Slightly motivated Very little & Slightly helpful \\
1 Strongly disagree & Not interested & Not motivated & Not at all & Not helpful \\
& & & & \\
\hline
\end{tabular}

Based on the findings discussed in the literature review, we expect:

- A positive correlation between the support from superiors and energy savings. Superiors supporting the energy saving competition publicly will help to mitigate the problem of competing priorities [5];

- A positive correlation between the interest of colleagues and energy savings. Interest in the energy saving competition is seen as a proxy for willingness to change energy use behaviour;

- A positive correlation between the motivation of colleagues and energy savings. Motivation is also seen as a proxy for willingness to change energy use behaviour;

- A positive correlation between observed behaviour change and energy savings. Though, it has to be noted that in this case the correlation will only be positive if a) employees change their energy use behaviour and b) energy team members are able to observe and assess it correctly;

- A positive correlation between how respondents assess the material distributed by the Compete4SECAP team and energy savings. This can be interpreted as indicator for the role the materials distributed by the Compete4SECAP partners had in the success during the energy saving competition.

We use Spearman's rank correlation coefficient $\rho_{\mathrm{s}}$, i.e. Pearson's correlation coefficient for rank values, to assess correlation. We use the built-in function of R [14] to calculate $\rho_{\mathrm{s}}$ and test if the correlation is significantly different from zero.

\section{Results}

\subsection{Energy Consumption during the Energy Saving Competition}

Results of energy savings competition are determined on three levels - buildings, municipalities and countries. In interpreting the results, we will mainly concentrate on percentage changes compared to the baseline. In three of the countries participating in the Compete4SECAP energy saving competition the methods described in the preceding section could not be followed entirely. In one of the countries, competition activities began late. In the others, occupancy and use of buildings changed and a technical defect caused an abnormal change in electricity consumption. Furthermore, in some cases it has been much harder than expected to collect reliable energy consumption data. Therefore, we concentrate our analysis 
on 61 buildings from Croatia, France, Hungary, Latvia and Spain for which we are reasonably sure that the methods described above have been followed.

We have recorded data for changes in heat consumption from 43 buildings. The other 18 buildings in our sample are not equipped with a heating system.

TABLE 4. CHANGE OF HeAt CONSUMPTION COMPARED TO BASELINE CONSUMPTION

\begin{tabular}{llllll}
\hline$n$ & Mean & Median & Standard Deviation & Max & Min \\
\hline 43 & $-6.7 \%$ & $-4.5 \%$ & $16.8 \%$ & $23.6 \%$ & $-39.8 \%$ \\
\hline
\end{tabular}

While the average reduction of heat consumption by $6.7 \%$ is consistent with the results of earlier studies, we also find a high standard deviation of $16.8 \%$ (see Table 4 ). The maximum value in the dataset is an increase of heat consumption by $23.6 \%$. The minimum value is a decrease of heat consumption by $39.8 \%$. This is twice the maximum value that a review found for likely savings due to combination intervention [4] and therefore considerably higher than values typically found in the literature. Yet, we know of a case in which the energy saving competition gave the impetus to lower the set point of the heating system by several degrees Celsius. This does result in substantial savings. Therefore, we decide to not discard any of the remaining values as outliers. This leaves us with 43 observations in Table 4 . Fig. 2 shows the changes in heat consumption grouped by country.

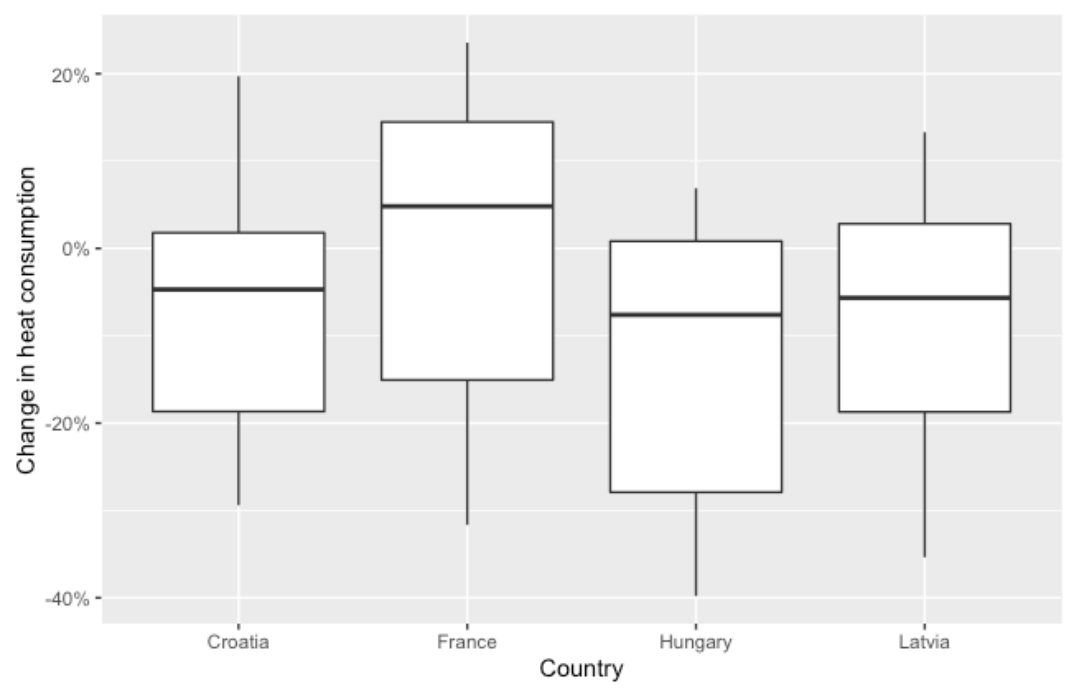

Fig. 2. Change in heat consumption by country.

Fig. 2 illustrates that the success of the energy saving competition differs between the countries in the competition. It also underlines that there have been large differences in the extent and direction of changes in heat consumption even within countries. In every country we find buildings that have a higher heat consumption in the year of the energy saving competition compared to the baseline. In France the median value amounts to an increase in heat consumption. Compete4SECAP project partners could identify possible reasons for this increase in heat consumption. These reasons range from a lack of resources the energy teams 
had to raise awareness to the substitution of energy team members during the competition. Yet, with the available data it was not possible to pinpoint definite reason in each individual case.

Data for the change of electricity consumption was available for 61 buildings. This data is summarized in Table 5.

TABLE 5. ChANGE OF ELECTRICITY CONSUMPTION COMPARED TO BASELINE CONSUMPTION

\begin{tabular}{llllll}
\hline$N$ & Mean & Median & Standard Deviation & Max & Min \\
\hline 61 & $-7.6 \%$ & $-7.5 \%$ & $12.6 \%$ & $23.9 \%$ & $-34.8 \%$ \\
\hline
\end{tabular}

On average, electricity consumption of buildings in the energy saving competition was reduced by $7.6 \%$. The standard deviation is lower than in the case of heat consumption, but still large with $12.6 \%$. Again, the minimum value (i.e. the largest decrease) in the sample is considerably larger than the value for combination interventions found in the literature [4]. Yet, as in the case of changes in heat consumption we decide against discarding any result as outlier. Fig. 3 shows the changes in electricity consumption grouped by country.

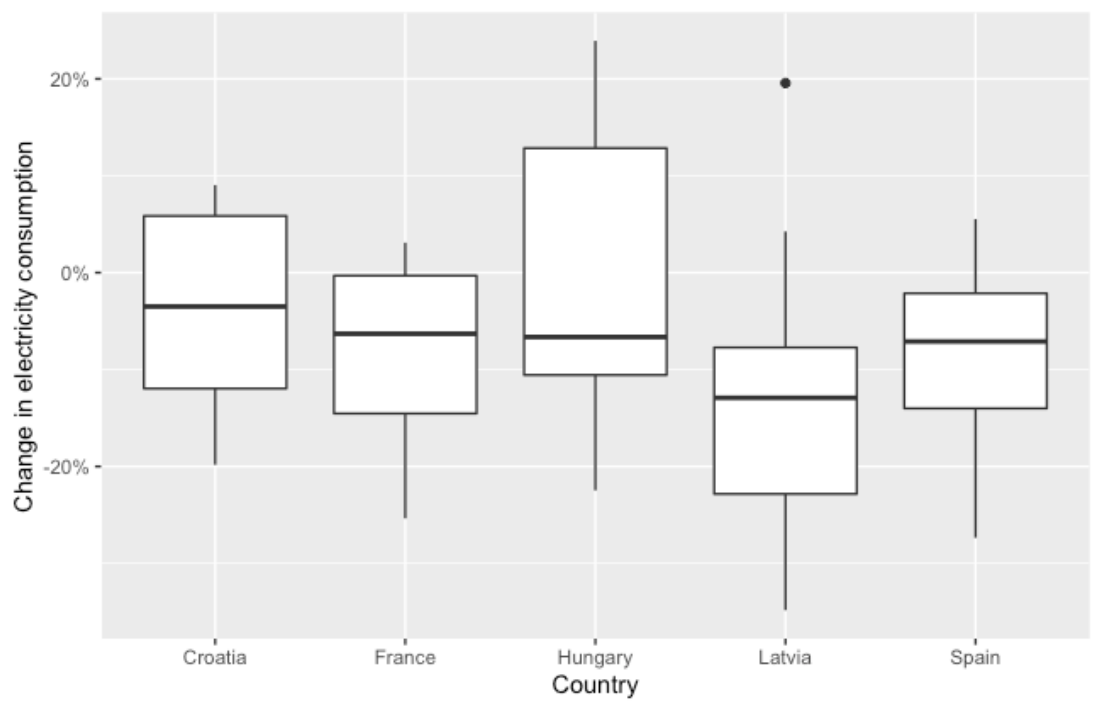

Fig. 3. Change in electricity consumption by country.

As in the case of heat consumption, Fig. 3 illustrates that changes of electricity consumption in the year of the energy saving competition differ widely even within countries. In four countries (France, Hungary, Latvia and Spain) at least one building achieved a reduction of its electricity consumption by $20 \%$ or more in the year of the energy saving competition. As was the case for heat consumption, each country saw buildings that had a higher electricity consumption in the competition year compared to the baseline. Possible reasons for this are similar to those named in the case of heat consumption.

Table 6 shows the results of energy saving competition in absolute terms as well as the change in energy consumption (i.e. heat and electricity combined) for each of the five 
countries. Please note that the results in Tables 4 and 5 and Fig. 2 and 3 are evaluated on the level of buildings while the change in energy consumption in Table 6 is evaluated on the country level.

Table 6. Net Electricity and Heat SAVIngs in the Year of the Saving Competition

\begin{tabular}{llllll}
\hline Country & $\boldsymbol{n}_{\text {electricity }}$ & Net electricity savings & $\boldsymbol{n}_{\text {heat }}$ & Net heat savings & $\begin{array}{c}\text { Change in energy } \\
\text { consumption }\end{array}$ \\
\hline Croatia & 12 & $32.8 \mathrm{MWh}$ & 8 & $122.0 \mathrm{MWh}$ & $-5.5 \%$ \\
France & 12 & $220.3 \mathrm{MWh}$ & 11 & $122.0 \mathrm{MWh}$ & $-7.4 \%$ \\
Hungary & 10 & $131.5 \mathrm{MWh}$ & & & \\
Latvia & 15 & $55.9 \mathrm{MWh}$ & 10 & $260.2 \mathrm{MWh}$ & $-9.9 \%$ \\
& & & 14 & $163.6 \mathrm{MWh}$ & $-8.1 \%$ \\
Spain & 12 & $194.2 \mathrm{MWh}$ & - & - & $-6.8 \%$ \\
\hline Total & $\mathbf{8 4}$ & $\mathbf{6 3 1 . 9} \mathbf{M W h}$ & $\mathbf{5 6}$ & $\mathbf{7 9 1 . 2} \mathbf{M W h}$ & $-\mathbf{8 . 4} \%$ \\
\hline
\end{tabular}

\subsection{Survey Results}

The second wave of the survey was conducted in January and February 2020, i.e. after the energy saving competition had ended. The survey was completed by 135 energy team members, of which one did not name the building he or she was responsible for. The remaining 134 energy team members came from 52 buildings, which corresponds to $57 \%$ of all the buildings in the energy saving competition. We have calculated the five scores that have been defined above for all 52 buildings:

- Support from superiors: Most respondents agreed that their superiors were interested in the energy saving competition, motivated to support it and were supplying the resources the energy teams asked for. The arithmetic mean for the support score is 3.7 , its standard deviation 0.8 . The maximum value is 5 , the minimum value 1.7 ;

- Interest: Most respondents estimated that a considerable share of their colleagues was at least fairly interested in the energy saving competition. The arithmetic mean for the interest score is 3.3 , its standard deviation 0.9 . The maximum value is 5 (i.e. one energy team member estimated that $100 \%$ of his/her colleagues were very interested), the minimum value is 1.3 ;

- Motivation: Again, most respondents thought that a large share of their colleagues was at least fairly motivated to support the competition. The arithmetic mean for the motivation score is $3.3(\mathrm{~s}=0.9, \max =5, \min =1.3)$. The small differences between the interest and motivation score may signal that it was hard for respondents to discriminate between interest and motivation;

- Behaviour change: Respondents were even more positive that their colleagues changed their energy use behaviour. The arithmetic mean for the behaviour change score is 3.6 $(\mathrm{s}=0.8, \max =5, \min =1.55)$;

- Helpful material: The helpful material score could only be calculated for 51 buildings. Overall, respondents considered the material distributed by the Compete4SECAP team 
as helpful. The arithmetic mean for the helpful material score is $3.7(\mathrm{~s}=0.7, \max =5$, $\min =2.1$ ).

We calculate Spearman's rank correlation coefficient for the correlation between the change in electricity and heat consumption and our scores separately and then test if each correlation is significantly different from zero. In calculating correlations, we only use data from five countries (Croatia, France, Hungary, Latvia and Spain) for the reasons explained above. We find all but one rank correlation coefficient to have the expected sign. The correlation between the change in electricity consumption and the helpful material-score is negative, but very weak and not significantly different from zero. The correlations between the other scores and the change in electricity consumption are weak or moderate, but significantly different from zero. Correlations between the change in heat consumption and the scores all have the expected sign, but are very weak or weak and not significantly different from zero. Table 7 shows the results of the analysis. These findings can be explained with the thesis that changes in electricity consumption were to a stronger degree caused by changes in user behaviour than changes in heat consumption. This assumes that the scores are proper indicators for changes in user behaviour.

TABle 7. Spearman's Rank CORRELATION BETweEn SCORES AND ENERGy SAVINGS

\begin{tabular}{lllll}
\hline & $\boldsymbol{n}_{\text {electricity }}$ & $\boldsymbol{\rho}_{\text {s, electricity }}$ & $\boldsymbol{n}_{\text {heat }}$ & $\boldsymbol{\rho}_{\mathbf{s} \text {, heat }}$ \\
\hline Support from superiors & 37 & $0.38^{*}$ & 25 & 0.09 \\
Interest & 37 & $0.42^{* *}$ & 25 & 0.35 \\
Motivation & 37 & $0.56^{* * *}$ & 25 & 0.22 \\
Behaviour change & 37 & $0.38^{*}$ & 25 & 0.27 \\
Helpful material & 37 & 0.01 & 25 & 0.22 \\
\hline Note: $* p<0.05, * * p<0.01, * * * p<0.001$ & &
\end{tabular}

\section{Discussion}

Our study corroborates several findings from the literature. Energy saving competitions can help to save considerable amounts of energy just through small investments and changes in the energy use behaviour of employees. In our study, electricity and heat consumption has been lowered by on average $8 \%$ and $7 \%$, respectively, in the year of the energy saving competition. This finding is consistent with earlier studies, though also at the lower end of likely energy savings due to combination interventions to change energy use behaviour [4]. The large standard deviation of changes in electricity and heat consumption we found in our sample is notable.

That the energy saving competition achieved energy savings is an important finding especially due to the fact that it was mainly executed with the local authorities' resources. Launching energy competitions as one of the actions of energy management system in municipalities delivers the same results as in other cases and can be introduced on an annual basis. Energy managers become important players to ensure direct energy savings in their public buildings with the training materials, energy monitoring and motivational instruments already available. 
For energy saving competitions to be successful at the workplace, engagement of all employees working in a building is helpful. Energy team members, who answered our survey, mostly saw their colleagues as interested in the competition, motivated to support it and changing their energy use behaviour considerably. This is documented by the average of the respective scores being between 3 (fairly interested, motivated, etc.) and 4 (interested, motivated, etc.). Most respondents also felt supported by their superiors, which is important in light of the competing priorities discussed by Bull and Janda [6]. The scores for support from superiors, interest, motivation and behaviour change of employees as assessed by energy team members exhibit a positive (if weak or moderate) correlation with the change in electricity consumption. The correlations between these aforementioned scores and the change in heat consumption are very weak or weak and not significantly different from zero. The support materials distributed by the Compete4SECAP team have been shown to be helpful as documented by an average score of 3.7. Yet, how helpful the materials were in the eyes of the energy team members was not correlated with the changes in electricity and heat consumption.

Nevertheless, there are several limitations of our study that have to be kept in mind when interpreting the results. It was not possible to follow the competition protocol to the fullest extent in every country. Collecting reliable energy consumption data for calculating baselines and saving success was harder than expected. The fact that reliable data on energy consumption can be hard to access or collect in the case of public buildings underlines that energy management system could be of great help to municipalities. The data from only five countries could be used in our analysis and large changes in energy consumption $( \pm 20 \%)$ do occur in the sample. Various reasons why these changes are probably due to actual variations and not due to measurement errors have been identified, but an unambiguous reason in every case could not been pinpointed. Another limitation is that the survey could only be conducted among energy team members. Therefore, there is only an impression of how interested, motivated, etc. most people working in a building seemed to others and not how they in fact felt. Energy savings have been corrected for outdoor temperatures, which make the estimation of energy savings more reliable and is a big advantage compared to other studies that have not done this. Nevertheless, a gold standard for estimating the impacts of energy saving competitions would be to have a randomised controlled trial, where buildings are randomly assigned to the trial group and a control group of buildings that do not take part in the energy saving competition. This was not possible in our project.

\section{ACKNOWLEDGMENT}

The research presented in this paper has been conducted with funding received from the European Union's Horizon 2020 research and innovation program under grant agreement No 754162. The authors thank the European Union for their support and their colleagues at B\&SU, the Cyprus Energy Agency, DOOR, Ekodoma, Eurovértice, GreenDependent Institute, ICLEI, MT Partenaires and SOGESCA for implementing the energy saving competition. We are grateful for the reviewers' comments. These comments have helped to greatly improve the paper. The sole responsibility for the contents of this paper lies with the authors. More information about the project can be found at https://compete4secap.eu/home. 


\section{REFERENCES}

[1] EU Buildings Database [Online]. [Accessed 15.09.2020] Available: https://ec.europa.eu/energy/eu-buildingsdatabase_en

[2] Jimenez-Bescos C., Oregi X. Implementing User Behaviour on Dynamic Building Simulations for Energy Consumption. Environmental and Climate Technologies 2019:23(3):308-318. https://doi.org/10.2478/rtuect-2019$\underline{0097}$

[3] Andor M. A., Fels K. M. Behavioral Economics and Energy Conservation - A Systematic Review of Non-price Interventions and Their Causal Effects. Ecological Economics 2018:148:178-210. https://doi.org/10.1016/j.ecolecon.2018.01.018

[4] Barbu A.-D., Griffiths N., Morton G. Achieving energy efficiency through behaviour change: what does it take? EEA technical report. Publications Office of the EU, Copenhagen, 2013. https://doi.org/10.2800/49941

[5] Staddon S. C., et al. Intervening to change behaviour and save energy in the workplace: A systematic review of available evidence. Energy Research \& Social Science 2016:17:30-51. https://doi.org/10.1016/j.erss.2016.03.027

[6] Bull R., Janda K. B. Beyond feedback: introducing the 'engagement gap' in organizational energy management. Building Research \& Information 2018:46:300-315. https://doi.org/10.1080/09613218.2017.1366748

[7] Gustafson C., Longland M. Engaging Employees in Conservation Leadership. Proceedings of the 2008 ACEEE Summer Study on Energy Efficiency in Buildings 2008:134-147.

[8] Metzger I., Kandt A., VanGeet O. Plug Load Behavioral Change Demonstration Project. NREL Technical Report. US: NREL, 2011.

[9] Murtagh N., et al. Individual energy use and feedback in an office setting: A field trial. Energy Policy 2013:62:717728. https://doi.org/10.1016/i.enpol.2013.07.090

[10] Dixon G. N., et al. Using Comparative Feedback to Influence Workplace Energy Conservation: A Case Study of a University Campaign. Environment and Behavior 2015:47: 667-693. https://doi.org/10.1177/0013916513520417

[11] Petersen J. E., et al. Electricity and Water Conservation on College and University Campuses in Response to National Competitions among Dormitories: Quantifying Relationships between Behavior, Conservation Strategies and Psychological Metrics. PLOS ONE 2015:10:0144070. https://doi.org/10.1371/journal.pone.0144070

[12] Vine E. L., Jones C. M. Competition, carbon, and conservation: Assessing the energy savings potential of energy efficiency competitions. Energy Research \& Social Science 2016:19:158-176. https://doi.org/10.1016/j.erss.2016.06.013

[13] Vadovics E., et al. save@work Evaluation Report: Lessons learnt for future sustainable energy projects aiming to change everyday behaviour. 2017.

[14] R Core Team, 2020. R: A language and environment for statistical computing. R Foundation for Statistical Computing, Vienna, Austria [Online]. [Accessed 21.09.2020]. Available: https://www.r-project.org 